\title{
On Iconic-Discursive Representations: Do they Bring us Closer to a Humean Representational Mind?
}

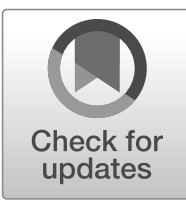

\author{
Guillermo Lorenzo ${ }^{1}$ (D) $\cdot$ Emilio Rubiera ${ }^{1}$
}

Received: 31 October 2018 / Accepted: 18 October 2019/Published online: 15 November 2019

(C) Springer Nature B.V. 2019

\begin{abstract}
This paper argues, contrary to Fodor's well-known position, that the iconic and discursive modes of representation are not mutually exclusive categories. It is argued that there exists at least a third kind of representation which blends the semantic properties of icons and the syntactic properties of discourses. We reason that this iconic-discursive genus behaves differently from other representational formats, such as distributed representations or maps, previously put forward as challenging Fodor's basic distinction. A reflection follows about how this kind of representation impacts on the Fodorian issues for which the original dual distinction was argumentatively instrumental, namely, the kinds of codes and possible inter-code relations accessible to the representational mind. The suggestion is put forward that iconic-discursive representations may facilitate trade-offs between the world and the representational mind, as well as between the differently complex levels of representation that mediate between percepts and concepts. We conclude that such aspects of the computational mind, which until now appeared to be stubbornly resistant with respect to a conciliation of Hume's empiricism and Fodor's computationalism, may be more easily accessed and understood taking advantage of the biosemiotics perspective and acknowledging the richness of the biosemiotics codes accessible to cognition.
\end{abstract}

Keywords Representational theory of mind · Icons · Discourses · Likeness · Compositionality

\section{Introduction}

It is unanimously claimed that 'intentionality' — x's property of being 'about' some other thing $\mathrm{y}$ - is one of the hallmarks of the mental (Brentano 1874/1973).

Guillermo Lorenzo

glorenzo@uniovi.es

1 Facultad de Filosofia y Letras, Universidad de Oviedo, Campus de Humanidades,

E-33011 Oviedo, Spain 
Nowadays, the most widely supported thesis for dealing with such an elusive property continues to be the Representational Theory of Mind (RTM), adumbrated in the mid twentieth century after the dismissal of behaviorist psychology. According to the TRM, the brain is a symbol-manipulation machine that works in a representational medium (Pitt 2018, Sterelny 1990; see Barbieri 2009, 2013, Beni 2017, for a biosemiotic approximation, and Chemero 2009 for some current dissenting approaches). The idea is tantamount to claiming that (complex) mind/brains are biosemiotic entities par excellence. Continuously with this claim, one may contend that disentangling the properties of mental representations, together with the kinds of computations that transform them for the purposes of different cognitive processes, is among the deepest tasks that Biosemiotics has to confront as a distinct scientific enterprise. With this general aim in mind, this paper deals with a very specific and basic aspect of the issue, namely, which kinds of symbols are accessible to the representational mind for dealing with in its internal endeavors.

The late Jerry Fodor, one of the founding fathers of the RTM and, indisputably, an authority in this particular subject matter, famously claimed that the mind works with two elementary modes of representation, namely, the 'iconic' and the 'discursive' classes — or 'genera,' to use Haugeland's (1998) term, which exhibit mutually exclusive properties, thus precluding any type of blended or mixed representational category from materializing (Fodor 2003, 2007, 2008). Such a chasm, Fodor's argument goes, has to do with the semantic properties of the corresponding symbolic vocabularies, but, ultimately, with the characteristics that compositionality exhibits in each case. The first goal of this paper is to argue against such a Fodorian thesis, showing that systems that include properties of the two basic representational regimes are not merely conceivable at a conceptual level, but also empirically attested. Moreover, they are not particularly exceptional. Section 2 of this paper is devoted to these issues, introducing, first, the relevant concepts and, then, supplying some instances of systems of this kind.

It is worth bearing in mind that Fodor's distinction was modeled as a way of addressing what we refer above as one of the deepest concerns for biosemiotics investigations, namely, the one deciphering the kind of mind-internal code capable of articulating systematic and productive thoughts. In pursuing such a demanding empirical issue, Fodor strategically focused on mind-external systems of representation (pictures) and systems with public, external correlates (natural languages), from which he derived relevant conclusions regarding the kind of representational system that might most aptly serve as the vehicle of internal thoughts with the above-mentioned properties - i.e. systematicity and productivity. In this paper, we shall follow a similar methodology. Section 3 is thus devoted to introducing an 'artificial' system of representation (similar to how Fodor referred to pictures as the prototype for iconicity), which according to our analysis shows the blending of interest. We subsequently argue (and offer a relevant illustration) in section 4 that the same combination may spontaneously emerge in natural systems with a dual external/internal character (similar to the way Fodor referred to natural languages as the epitome of discursivity).

Like Fodor, we also believe that if our observations and conclusions are on track, then some important lessons can be drawn regarding what kinds of codes are, as a matter of fact, accessible to the biological substrate of the brain in order to fulfill its representational needs. In section 5, we shall consequently explore the impact of 
leaving behind the Fodorian dual iconic/discursive divide on a more accurate understanding of the biosemiotic capacities of brains than hitherto possible. Some concluding remarks will close the paper.

\section{The Basic Distinction}

In a series of publications at the beginning of the twenty-first Century, Jerry Fodor adhered to the thesis that there exist two main different, mutually exclusive kinds of representation, namely, 'discursive' representations and 'iconic' representations (2003: 37-39, 2007: 107, 2008: 171). As representations, they obviously share the 'aboutness' property - i.e. the intriguing quality of being surrogates of some other thing or state of things, as well as the 'decomposability' property - i.e. the quality of being possibly made of component parts. Put together, these properties lead to the entailment that representations partake in both external (or 'semantic') and internal (or 'syntactic') relations, which respectively project them onto the outside (e.g. the world) or onto themselves (e.g. part-to-part adjacency, long-distance or embedded connections, etc.). What ultimately distinguishes these categories form each other is how such relations instantiate in the different representational media. The difference appears to be constrained by two conceptually isolable parameters, which contribute a kind of litmus test for identifying representations as belonging to the discursive or the iconic kinds. The parameters themselves, as well as the values specifically instantiated by the two basic representational modes, are summarized in Table 1, which roughly parallels what Haugeland (1998) refers to as the 'canonical account' of representational genera.

Obviously enough, Table 1 portrays our own interpretation about how the Fodorian distinction works. We are not in a position to assert whether Fodor would agree on such parameterized rendition, although we do believe it to be implicit in Fodor (2007: 107108). However, this is not crucial for our point. A more charitable reading of Fodor would be that he only thought one axis to be ultimately relevant - namely, the type of compositionality axis (see below in this section), which per se makes icons and discourse mutually excluding. Our point is that they are not, leading us to suggest that the kind of parameterized model shown in Table 1 is a correct, albeit incomplete, one.

On the one hand, the semantic and syntactic properties of primitive units are sourced differently in discursive and in iconic systems. For concreteness, discursive systems are self-sufficient, in the sense that what primitive units mean and how they connect to each other is established by the system itself - thus 'from within.' Fodor refers to natural languages as the epitome of this kind of representation, in which minimal meaningful units (morphemes) and the means for combining them meaningfully (morpho-syntactic rules) are encoded in a language-particular lexicon and grammar. Knowledge of such

Table 1 The two basic parameters for identifying kinds of representations

(1) Type of semanticity

(2) Type of compositionality

\begin{tabular}{lll}
\hline $\begin{array}{l}\text { Discursive } \\
\text { Iconic }\end{array}$ & from within & proper parts \\
from without & mere parts \\
\hline
\end{tabular}


inventories/procedures can only be attained by adhering to the community of users of the corresponding linguistic conventions. Thus, one needs to have some acquaintance with the Basque speaking community in order to know that liburu means 'book' in Basque, and that it typically precedes the verb when expressing the 'theme of' the event represented by the verbal phrase, as in liburu bat oparitu diat 'to offer a book'; lit. 'book DET give-as-a-gift AUX.' In iconic systems, however, units and the means for putting them together are dependent on how external correlates are organized — thus 'from without.' So, for example, in pictures, the prototype of iconicity according to Fodor, meaningful units and relations are fixed on the basis of analogies with things and states of affairs external to the representation. As a consequence, it is relatively easy to grasp what a particular picture is about without previous acquaintance with similar pictures. $^{1}$

On the other hand, discourses and icons decompose differently into lower units of analysis. In the former case, there exist particular ways of decomposing a representation, what is thereby obtained not being, in a true sense, a part of the representation. In the case of, for example, a sentence in Basque — Nik hiri liburu bat oparitu diat 'I gave you a book as a present;' lit. 'I to-you book DET give-as-a-gift AUX,' a fragment like hiri liburu 'to-you book' is not a component — or 'proper part' — of the representation, while liburu bat 'book DET' is. Pictures function differently, as, no matter how one chooses to decompose one, what is obtained are parts all the same. Consequently, there is an indeterminate number of ways of decomposing an icon and still obtaining parts of it: Icons lack proper parts; they only have 'mere parts.'

Fodor acknowledged that his usage of the "icon' concept was rather "idiosyncratic" (Fodor 2008: 171), probably because he believed it to be somehow a departure from the Peircean orthodoxy. However, we believe the opposite to be true, namely, that Fodor's 'iconic' representations are Peircean iconic representations through and through. Perhaps, Fodor believed that by emphasizing the syntactic over the semantic facet of representations — as he certainly did (Fodor 2008: 171), he was departing from Peirce's characterization of iconicity, which is more focused on the semantic dimension. According to the aspect of Peirce's characterization that remained the most stable throughout the different phases of his theory of signs (Atkin 2013), what defines an 'icon' is that it stands for its object by virtue of some shared quality - i.e. 'from without' (not Peirce's qualification); 'symbols,' on the other hand, are established on the basis of conventional, self-servient connections - i.e. 'from within' (not Peirce's qualification). This probably explains why discursive representations are particularly prone to imposing their own logic on represented domains - and thus more likely to be stimulus-independent and open-ended in expressivity, in ways not as clearly accessible to iconic representations — which appear to be more stimulus-dependent and constrained by the represented domain. In any event, while this certainly speaks of the close interconnection between the traits corresponding to each of the parameters of differentiation in each particular representational regime - which led Fodor to conclude that the compositionality criterion is prevalent (Fodor 2008: 171), this does not

\footnotetext{
${ }^{1}$ Haugeland (1998) aptly settles the contrast by saying that icons are made of features that are disposed relative to each other preserving the way worldly correlates do, while discourses do away with such principle of organization, so features become self-sufficient in representations.
} 
mean that they are conceptually indistinguishable. In fact, both parameters matter and are equally necessary for definitional and descriptive purposes.

Regarding this, the objection might be raised that Fodor (2008: 174) explicitly says that "it can't be assumed that icons ipso facto resemble what they represent," and that this should prevent us from considering the first axis as relevant. But note that Fodor introduces this comment merely to open the class of icons to representations like graphs, which are not based on 'resemblance' but on an alternative class of 'likeness,' not to deny that icons generally owe their semantic character to some external quality, which graphs certainly also do. It should be remembered that Peirce, under the overarching category of 'hypoicons,' already distinguished between icons that represent by incorporating 'simple qualities' of the object ('images'), icons that represent by incorporating 'relations' of the object ('diagrams'), and icons that represent by incorporating 'parallelisms in something else' ('metaphors') (Peirce 1931 CP 2.274ff: 157); see Farias and Queiroz (2006).

The most important thesis that Fodor (2007: 109-110) endorsed as connected to his dual distinction was that discursive representations are able to encode logical forms, which iconic representations are not. The reason is that in the absence of proper partitions, the kinds of asymmetries that pave the way to the expression of such relations - as being 'an argument of' some predicate or other, being 'under the scope of' some variable binding operator or other, being 'a token of' some type or other, and so on and so forth - cannot be represented. In other words, and this is the point that Fodor was most eager to stress, discourses offer the means for conceptualization, but icons do not (Fodor 2007: 110). ${ }^{2}$ So, in a nutshell, icons offer themselves as an invaluable proof that a natural kind of non-conceptual representations may exist (Bermúdez and Cahen 2015). Whether such a kind exists at all is an empirical matter that Fodor deferred to experimental psychologists (Fodor 2007: 105). In any event, it was Fodor's contention that an unconscious perceptual level of iconic pre-conceptual content can be said to exist and experimentally explored.

Fodor made it clear that the distinction between discursive and iconic representations is probably not an exhaustive one: "I leave open the question that some kinds of representation are neither iconic nor discursive" (Fodor 2007: 107). ${ }^{3}$ Here, we shall

\footnotetext{
'Fodor's use of the term 'discursive' (as well as Haugeland's 1998 'logic' surrogate) may be misleading in certain uses, for it correctly applies to levels of analysis where, at first glance, it appears to be alien. For example, writing systems are well behind any level of analysis that one would be tempted to refer as 'discursive,' yet many of them qualify as 'discursive' in Fodor's sense. For the sake of illustration, think of the following series of Serbo-Croatian graphemes: $<\mathrm{c}>$ (voiceless alveolar sibilant affricate), $<$ ć $>$ (voiceless alveolo-palatal sibilant affricate), $<\check{c}>$ (voiceless palato-alveolar sibilant affricate). It seems clear that they comprise a basic 'c' component, while the stroked "' and "' components stand for extra, more nuanced related features. Despite the low level of linguistic analysis to which these kinds of writing systems apply, they exhibit, in Fodor's sense, 'discursive' organization. The claim can also be safely made that they 'conceptualize' the phonetic domain that they discursively represent. See below (fn.7) for a short parallel comment on non-alphabetic writing systems.

${ }^{3}$ For example, Haugeland (1998) suggests the kind (or genus) of 'distributed' representations and he refers to holographic images as an illustration. In holograms, each point in the holographic representation stands for each part of the represented scene, and the other way around. Therefore, they clearly function differently from icons in terms of the 'type of compositionality' axis; yet holographic representations are clearly iconic-like in terms of the 'type of semanticity' axis, as they clearly exhibit a certain kind of 'likeness.' Complementarily, connectionist networks can be used as an example of representations that do not exhibit any kind of 'likeness,' despite purportedly lacking proper parts.
} 
follow suit and do not touch this particular aspect of the issue. What interests us here is Fodor's further strong claim: "that a representation is either entails that it is not the other" (Fodor 2007: 107) - i.e. that the two basic modes of representation are mutually exclusive. It would therefore appear to follow that a kind of representation should not exist capable of blending or mixing the parametric values specifically associated to the basic categories. In this, we cannot come to terms with Fodor, for we claim that a kind of representations actually exists that exhibits discursive and iconic qualities all together.

\section{Iconic Discourses}

Logically speaking, the basic units of a system of representation could obtain their distinguishing kind of semanticity from within, yet the resulting representations could be composed of mere parts; and similarly, the basic units of a system could obtain their distinguishing kind of semanticity from without, yet the corresponding representations could consist of proper parts. What kinds of representation actually exist and how they are classified is an empirical matter — as Fodor himself acknowledged. However, Fodor claimed that discursive and iconic kinds of semanticity are mutually exclusive and, therefore, such logical possibilities should not, in principle, arise. The goal of this and the following section is to argue on empirical grounds that Fodor's claim was wrong. With this aim in mind, we shall use Fodor's argumentative strategy of first pinpointing a prototypal artificial representative of one of the relevant categories, paving the way to the further suggestion that it may also instantiate naturally.

We have specifically focused on systems that putatively combine that their units are meaningful by external — from without - means with the quality that their representations admit analyses in terms of proper parts - contrary to Fodor's predictions scheme; Table 2. We will refer to these systems as 'iconic discourses.' In this section, we introduce instances of representations taken from an artificial system currently in use for certain practical concerns, which according to our analysis belongs to the relevant class. The next section will be devoted to suggesting a natural representative thereof.

The source of the illustrations is a working document on "Tactical Signs" (Taktische Zeichen), which emanated from the Permanent Conference on Disaster Reduction and Emergency (Ständige Konferenz für Katastrophenvorsorge und Katastrophenschutz), dated in Köln 2003 (henceforth, SKKK DV 102). This document contains a detailed catalogue of visual signals aimed at serving for purposes related to the prevention of, and dealing with, catastrophic and emergency situations. While not all the signals

Table 2 An extension of Fodor's (2007) representational typology

(1) Type of semanticity

from within

from without

Iconic

Iconic-discursive from without

mere parts

proper parts 


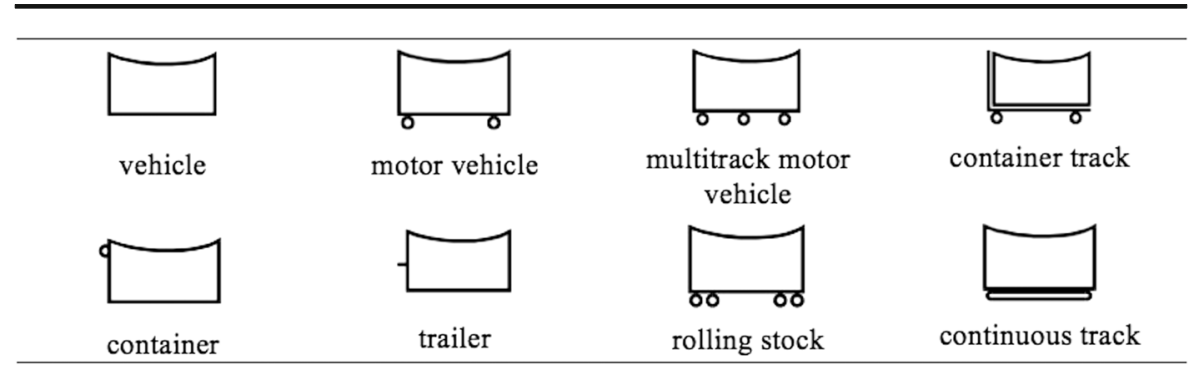

Fig. 1 Representations for wheeled land vehicles. Source: Taktische Zeichen of the Ständige Konferenz für Katastrophenvorsorge und Katastrophenschutz

encoded in the document exhibit the same formal properties, many of them can be said to exhibit the desired conjunction of representational properties. For example, among the system of signs for representing objects (SKKK DV 102, 14ff), one finds a subsystem for representing wheeled land vehicles (SKKK DV 102, 14-15). Figure 1 offers a sample of such signs, as well as a specification of the associated meaning.

One might argue that the sign corresponding to the general category for vehicles does not bear much resemblance any specific vehicle. This is undoubtedly true. However, it is also clear that it has not been selected to fulfil this role completely at random, for it could not serve the purpose without a vague resemblance to a vehicle. Users probably do not capture at first sight the idea of 'vehicle' simply by being exposed to the left upper sign of Fig. 1, but the resemblance clearly increases as soon as it is observed in the other signs. An informal survey by the authors served to demonstrate that when shown together, the signs were easily identified as representations of vehicles. These signs thus owe their semantic kind to resembling objects external to the system - i.e. from without. According to the first parameter of Table 1, they are correspondingly icons. But unexpectedly, according to Fodor's thesis, they are not made up of mere parts but rather of proper parts and thus are also discursively organized. Let us take a closer look with the help of Fig. 2 as the reference point.

Again, if one takes any individual sign (e.g. the one for 'vehicle'), the conclusion may be reached that if anything it only decomposes into mere pieces: i.e. no particular partition of the figure provides the right partition of it, but rather it can be divided in an indefinite number of different ways. Even if one takes another apparently more complex figure (e.g. the one for 'continuous track' in Fig. 1), no reason exists that guarantees that by dividing it into a lower (ii.) and an upper part (i.), proper parts are obtained. However, things change as soon as a series of figures are viewed jointly, for obvious proper partitions can then be easily detected. To be more precise, it becomes clear that $\mathrm{i}$. is in fact a recurrent component piece of all the figures in Fig. 1, that iii. recurs in many, but not in all the figures, or that iv., v., ii., and vi., appear in just one figure of the sample. Thus one deduces that the sample contains one-component figures

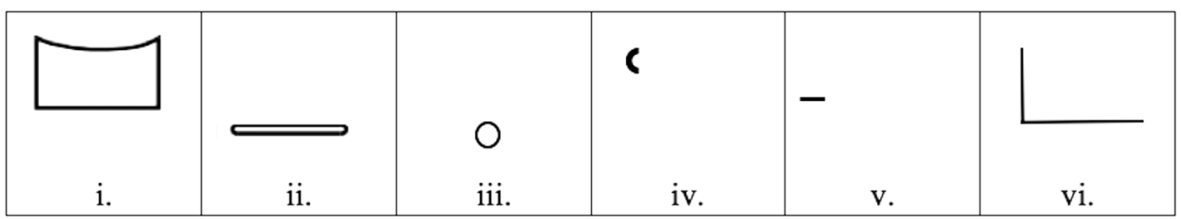

Fig. 2 Decomposition of the representations for wheeled land vehicles of the SKKK DV 102 
(namely, the one for 'vehicle'), two-component figures (e.g. the one for 'continuous track'), three-component figures (e.g. the one for 'motor vehicle'), four-component figures (e.g. the one for 'container track'), and so on. In other words, one discovers that the figures are not indefinitely decomposable into as many parts as one may decide to divide them. Crucially, one also crucially deduces the centrality of $i$. in relation to any of the other pieces, which each modify the former in a different way. In other words, the figures appear to show an asymmetry or hierarchy (actually, a 'head-modifier(s)' pattern) between their component parts. To conclude, they follow a pattern of organization into proper (i.e. not mere) parts and exhibit a rudimentary but nevertheless bona fide logical form. As a result, the system aptly categorizes items as instances of one kind of vehicle or other, with one or another kind of components. ${ }^{4}$

It is important to clarify and to stress that, in these examples, it is not just the case that the basic vocabulary (Fig. 2) is iconic, but that, when put together (Fig. 1), the resulting complex icons behave discursively and are apt to conceptualize. The situation would in that case be similar, for example, to cases in which an arbitrary word like 'exit,' a Peircean symbol if simply considered as an item of the English vocabulary, appears printed on a reflective surface above a door. Thus framed, the word is not to be interpreted as a symbol anymore. ${ }^{5}$ It does not logically conceptualize this something 'as' a door, but it behaves as a Peircean index in charge of guiding people in an emergency situation - a task for which conceptualization becomes irrelevant. ${ }^{6}$ The situation would also be similar to Haugeland's (1998: 176) example of a model floor made of little wooden pieces which the same designer may reuse to compound other model floors. Note that in this example the higher-level figure continues to merely behave as an icon - Haugeland himself agrees on this (1998: 184) — which is not doing any conceptual/logical job. It merely serves as a reference point or guiding pattern, a task for which conceptualization is certainly of no use. In contrast to these examples, our cases illustrate the different situation in which icons serve to compose higher level units that continue to be icons. Notwithstanding, their being icons does not prevent them from having conceptualizing powers.

The position of maps regarding these kinds of representational musings has traditionally been the object of much discussion - and for good reasons, as they appear to instantiate a kind or genus apart, with the potential of questioning the standard or canonical view of Table 1 . Whilst agreeing with this view, we also believe that this is so

\footnotetext{
${ }^{4}$ To a certain extent, the system resembles the much more familiar and studied case of traffic signals, which also exhibit a particular kind of compositional structure. However, two main differences separate them, making our suggested illustration particularly worth consideration. Firstly, traffic signal comprises both iconic and non-iconic elements as their basic units (e.g. the outline of a cow resembles a cow, but a red triangle does not resemble a dangerous thing); in contrasts, our SKKK DV 102 signals are fully made of basic icons. Secondly, the compositional outcome of traffic signals are not icons (taken as a whole, they do not mimic the referred circumstance), whilst the SKKK DV 102 signals continue to be bona fide icons.

${ }^{5}$ In Haugeland's (1998) terms, the word is not a 'representation' any more - and logically, not a symbol, but the 'record' of a representation/symbol. We are grateful to an anonymous reviewer for pointing out the desirability of clarifying this.

${ }^{6}$ An anonymous reviewer interestingly suggests that such a combination of a symbol and an index makes this example an instance of Pierce's 'dicising' category (Stjernfelt 2015). As a consequence, it is a kind of proposition, which does not refer to a certain location as an 'exit,' but to the potential action of getting out through it. In any event, whilst it is clear that propositions presuppose some kind of syntax, it is not at all clear that the syntax of a dicising like that of our example provides the means for constructing such a meaning compositionally.
} 

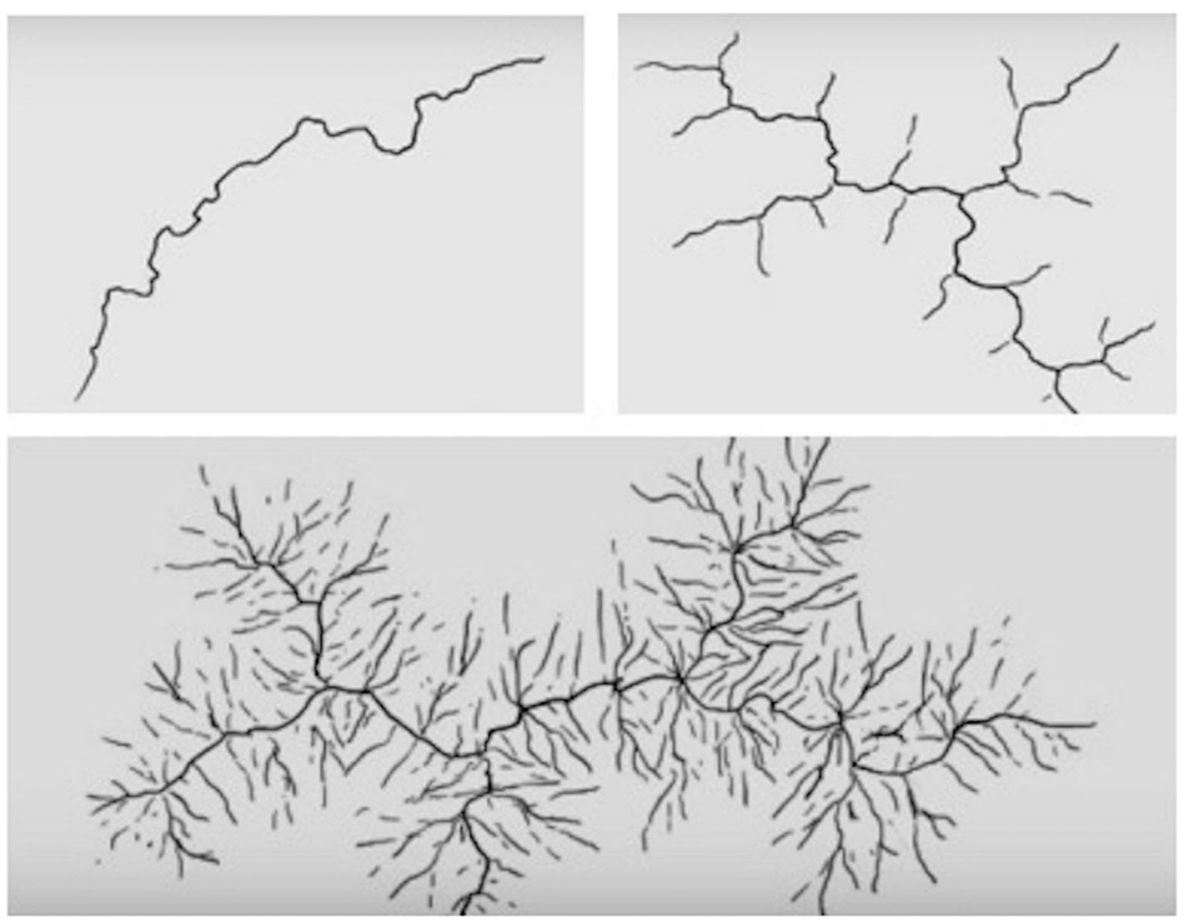

Fig. 3 Three increasingly complex steps for mapping a mountain system

for reasons different from the ones that we want to stress in this paper. We believe maps to be a good illustration of how icons may represent logical relations and, correspondingly, complex conceptualizations of the represented domains. ${ }^{7}$ However, they work differently from our suggested class of iconic discourses, as they appear to do so without necessarily entailing a proper discourse organization of lower level icons. This certainly is a strong challenge to Fodor's contentions, but not of the kind that we are attempting to illustrate here.

Let us take the specific case of how mountains may be translated into a map. For example, a given mountain system may be represented, first, by a line that runs from crest to crest of the mountains in the range (Fig. 3, upper left-hand image) and then secondary lines departing from the main one on both sides may represent lateral ridges or spurs (Fig. 3, upper right-hand image). Adding more in detail lines and shades may give the idea of their characteristic escarpment or spreading, and by making lines irregular, one may translate the idea of each mountain's uniqueness - Fig. 3, lower image. For the sake of our illustration, no more details need to be added. From the technique above, figures more and more resembling mountain systems will emerge as in Fig. 3.

\footnotetext{
${ }^{7}$ More debatable is the kind of logic that they instantiate. For example, Rescorla (2009) claims that it is not of a Fregean/Tarskian predicative kind, contrary to Casati and Varzi (1999). See Kulvicki (2015), for a somehow conciliatory position. The issue is not of crucial importance for our specific concerns. For a contrasting position, see Sellars (1979: 117-118), who contends that maps are logical pictures only parasitically, namely, through the mediation of statements like 'Chicago is between Los Angeles and New York.'
} 
Note that maps certainly appear to be capable of expressing logical/conceptual relations: e.g. that some mountain tokens belong to the same mountain system, rank in a certain way in terms of relative height, locate relatively to each other in a certain, transitivity-respecting way, etc. Yet they are iconic through and through, for representations incorporate the corresponding relative properties of the represented domains isomorphically - i.e. as patterns of relative properties in the representations themselves (Haugeland 1998); see fn.1. However, maps perform their logical jobs by means other than those of our suggested iconic discourses. For one thing, unlike discourses, none of the increasingly complex images of Fig. 3, even if each one is already a map, decompose into proper parts, including our iconic ones. If anything, they are based on a 'recording' procedure, in Haugeland's (1998) sense, that may be repeatedly applied to generate icons; however, they are clearly not based on repeated combinations of prepackaged icons, comparable to how icons in Fig. 1 are based on those of Fig. $2 .^{8}$

Maps are certainly of the utmost interest, as they certainly challenge Fodor's stipulations. It is no wonder they have been the focus of much attention in the literature - see, for example, Camps (2007) and Johnson (2015). However, they are beyond the scope of this paper, as the way they challenge the canonical view on representational kinds differs from that of iconic discourses. Only the latter category provides, according to our interpretation, a bona fide admixture of iconicity (from without semanticity) and discursiveness (proper decomposition). Artificial, man-made systems clearly display such a combination. ${ }^{9}$ The next question is to find out whether the same kind of systems can also be found 'in the wild.'

\section{Natural Iconic Discourses?}

Sign languages of deaf communities - more than 130, according to our survey of The Ethnologue; 19th edition — are as natural as the approximately 7000 spoken natural languages registered by the same source. ${ }^{10}$ Save for their transmission channel (kineticvisual as opposed to oral-auditory), they are organized not very differently in terms of kinds of units, rules, and so on. It is also a well attested fact that the parts of the brain in charge of controlling the production of these languages are to a great extent the same, ${ }^{11}$ and that signers and speakers may be affected by the same kinds of aphasic deficits (Poizner et al. 1987; Hickok et al. 1998). Sign languages, therefore, qualify as natural systems of representation exactly the same as spoken languages. However, sign

\footnotetext{
${ }^{8}$ We believe this to be the intuition that Rescorla (2009: 198) tries to capture when he defines maps as unified representations, wherein geometrical relations bear representational import.

${ }^{9}$ Non-alphabetic writing systems like the one associated to Chinese, mostly try to capture minimal semantic distinctions pictorially, thus qualifying, both intuitively and technically, as 'iconic.' Yet this doesn't prevent these low-level icons from entering into compositional arrangements with other icons belonging to the same level of analysis, the output of which, corresponding to the representation of words, however comprise 'proper parts' and thus qualify as 'discursive', again contradicting Fodor's stipulation. See Sampson and Chen (2013) for further valuable information.

${ }^{10}$ The Ethnologue is the most qualified and commonly quoted catalogue of the languages of the world. See https://www.ethnologue.com/.

${ }^{11}$ Relevantly to the point to be made in this section, parts of the brain are also recruited in the case of sign languages, but not in the case of spoken counterparts, which have to do with spatial cognition. See Hickok et al. (1998) and Campbell et al. (2007).
} 


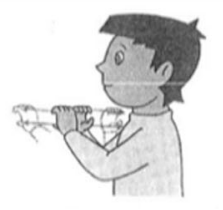

bus

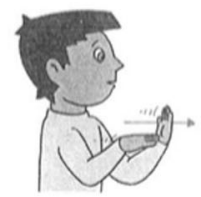

truck

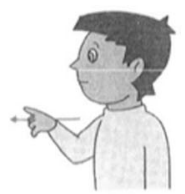

airplane

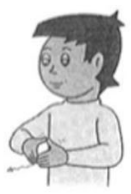

boat

Fig. 4 Some signs for representing forms of transportations in SSL. Source of the information: Cecilia Tejedor, Antonio (2004). Mil palabras con las manos... del léxico signado español [One Thousand Words with the Hands... of Spanish Sign Lexicon]. Madrid: CEPE

languages cannot be thought of as prototypal instances of discursive representation, in contrast to Fodor's consideration of spoken languages, as many individual signs, as well as some combination patterns, owe their semantic properties to external - from without - motivation. What follows is a brief analysis of a fragment of Spanish Sign Language (SSL), namely an analysis of a few individual signs. Conclusions, even at this low-level of analysis, will suffice to capture the whole point. ${ }^{12}$

For the sake of clarity, the selected fragment is again related to forms of transportation, thus providing a good point of comparison with the signs of the artificial system commented on in the previous section. Again, what one finds in this particular referential domain may not appear particularly revealing at first sight. For example, we are informed that by putting the two hands together to form a letter ' $\mathrm{C}$ ', joining the little finger of the right hand with the forefinger of the left hand, and then moving the left hand forwards and the right hand backwards, one obtains the sign that represents a bus. Things become a little clearer when we are also informed that, for example, with the left hand upwards forming a right angle with the right hand in front of the face, we represent a truck by moving the angle forwards. Or, to offer a final example, that with the little finger and the thumb of the right hand extended, while the rest of the fingers remain retracted, the sign for an airplane is obtained by moving the hand forwards (see Fig. 4).

It thus seems clear that all the signs of the sample incorporate (1) some kind of forward hand movement as a way of representing the basic idea of 'transportation,' with (2) details of the hand or of the movement itself as a way of qualifying it. It would also, therefore, seem reasonable to conclude that (1) stands in a relation with the whole figure identical to the representation of the basic idea of 'vehicle' in the illustration of the previous section. Thus, figures comprise a central component together with certain modifying motives: i.e. they incorporate a 'head-modifier' structure of sorts. In other words, they do not merely decompose, but rather they decompose into proper parts. Yet they obtain their semanticity from without, e.g. resembling the forward movement of a moving vehicle, the wings of an airplane, the cab and platform of a truck, the tube-like form of a bus, etc. To conclude, they combine iconic and discursive qualities, contrary to Fodor's expectations.

Some details need to be stressed regarding the nature of sign languages in order to strengthen our point. Sign languages are not purposefully invented to aid communication

\footnotetext{
${ }^{12}$ Let us simply note that a whole sentence may also be (from without) iconic in sign languages. For example, in American Sign Language, a sentence roughly corresponding to 'I give to you' is signed by approaching the right hand (closed, palm up - as if grasping an object at chest hight), starting from the signee and approaching the interlocutor - the opposite direction for signing 'you give me'. See Hickok et al. (1998).
} 
in deaf communities; rather, thry emerge spontaneously as soon as deaf people enter into contact with each other in relatively large communities. They normally originate from informal 'home sign systems' used in familiar environments or within small groups (Goldin-Meadow 2003), which may abruptly become stylized and regularized as soon as they are shared by more and more people and, crucially, when people are exposed to them from early infancy (Senghas et al. 2007). At that point they are completely indistinguishable, save for the qualifications above, from spoken languages. Not all individual signs of a sign language obey the same pattern of semanticity. To be fair, some of them may be overtly iconic, while some others may be completely discursive. However, two points need to be stressed regarding this. On the one hand, many signs actually obey the above-mentioned pattern, which means that it is not incongruent for a natural system of representation to spontaneously evolve iconic-discursive items. On the other hand, exactly the same as spoken languages, sign languages have the resources to productively combine minor representational units into bigger, high-level ones - the homologues of phrases, sentences, and so on, which means that bona fide representations at such levels can easily build from partially iconic underpinnings.

The conclusion is again clear. Contrary to Fodor's contention, being iconic does not entail not being discursive at the same time - and the other way around. Iconicity and discursiveness are not mutually excluding properties of representations, separated by a kind of gap. Being iconic and being discursive are not monolithic, refractory properties. No a priori reason exists that prevents such qualities from cross-over effects. Systems of representation exist, both created for special purposes (or artificial) and spontaneously emerged (or natural), that instantiate, at least, the class 'from without/proper parts,' contrary to Fodor's a priori stipulation.

\section{Consequences for Theories of Perception and Thought}

Chronologically speaking, Fodor (2007), on which our attention has been mostly focused, is a very interesting text, because the elaboration of the iconic/discursive divide that Fodor puts forward there functions as a link that strengthens the unity of his (2003) and (2008) enterprises. Central to both books is the question whether there exists a perceptual layer which operates on representational grounds other than the ones used by thought. Drawing on his dual, mutually exclusive distinction, Fodor concludes that thought is built out of properly decomposable expressions - thus, discursively, while forms of early perception work as registrations of the outside, onto which no proper patterns of organization are imprinted - thus, iconically. Perception is only elaborated at a later stage, by means of conceptual enrichment processes. Thus, Fodor's position is that a pre-conceptual, perceptual 'given' arguably exists, which offers a suitable bridge for filling the gap between the 'world-in-itself' and the 'world-as-conceptually-represented' (Bueno 2013). Icons appear to be the optimal format to serve such a bridging function, since, on the one hand, they are malleable enough to accommodate to the demands of the environment, ${ }^{13}$ while, on the

\footnotetext{
${ }^{13}$ In Kulvicki's (2003) terminology, iconic representations appear to be particularly apt for fulfilling such a task given their higher degree of semantic richness and syntactic sensitivity, which makes them more replete relative to discursive representations. However, it also appears to make them less computationally tractable, an aim for which discourses, in contrast, appear to more flexible.
} 
other hand, they amount to a first representational medium apt to be re-represented by the imposing, higher-level resources of discursively organized thought — see Sellars (1979: 120-122) for some seminal ideas in the same direction. This is how, for example, Fodor and Pylyshyn (2015) envision the progression from a realm of 'as-less,' brute-causally induced representations, which lays the groundwork for further conceptually enriched representations with the vocabulary proper of different cognitive domains - vision, language, etc.

The third, middle ground modality of iconic-discursive representation suggested here, whilst convincing enough, brings with it the potential to complicate the picture above: On the one hand, the possibility arises that iconic-discursive representation may in fact be the world-concepts go-between - i.e. a kind of partially bare, partially clothed perceptive style. On the other hand, the possibility also arises that there exists not a single, all-powerful, discursive Language of Thought (LOT), but that conceptual enrichment and central thought may also be attained by partially iconic means. ${ }^{14}$ The question, as repeatedly stressed by Fodor, is ultimately empirical. The point of our contribution is that there appears to be no a priori reasons for constraining the search space as narrowly as Fodor did. A similar conclusion was reached by Balog (2009), who claims that Fodor's cognitive division of labor "follows only if the two possibilities he considers - that the states carrying information [...] are conceptual or that they are iconic — are the only ones. But the disjunction isn't exclusive" (Balog 2009: 319; see also Haugeland 1998: 175, for a previous similar statement).

From a historiographical perspective, the putative iconicity of the ultimate perceptual background of cognition is the main foundation of Fodor's disagreement with Hume's naturalist project, towards which Fodor is sympathetic in all other respects (Fodor 2003). For if the realm of impressions (aka experience) is a realm of iconic representation, as Fodor believes it to be, then the further realm of ideas (aka discursively organized concepts) cannot simply derive from copies of the former, contrary (or allegedly so) to Hume's thesis. The issue is however contentious, since one of Hume's central claims was that the relation between the environment and impressions/ perception is an inscrutable one (Hume 1783/2007 T: 1.4 .2 .54 ), and consequently the mind-scientist will never be able to judge it as being iconic or otherwise (Owen 2009). Fodor's disagreement is thus not justified. Fodor famously adhered to the thesis that the way concepts relate with their external correlates is a metaphysical, maybe inscrutable sort of relation; yet he also admitted perceptive fields to be within the scope of what may be understood as continuous with the physical realm (Fodor 1998). One of the lessons of this paper is that there seems to be no a priori pressure to believe that the realm of impressions/experience is opposed to the realm of ideas/concepts in terms of the mutually unreducible iconic/discursive opposition. Therefore, a Humean-like solution to the relation between impressions/experience and ideas/concepts, based on some version of the copy theory, is maybe not to be discarded out of hand. Impressions could be iconic, carving nature at its joints, yet discursively decomposable, making it more easily translatable into further fully compositional conceptual thoughts. The issue is

\footnotetext{
${ }^{14}$ Two candidates immediately come to mind, namely, 'constructions,' in the sense of Construction Grammar (Goldberg 1995), and 'schemes,' as conceived of by Cognitive Linguistics (Johnson 1987). In both cases, prepackaged skeletal structures are suggested as iconically capturing the bare bones of a wide range of different actions, events, and so on. Given their iconic roots, they easily generalized to partially similar, but partially departing domains; yet they show the kinds of embedding effects proper of discourse organization.
} 
admittedly empirical. The bottom line is that possibilities appear to be wider than Fodor's dualistic stance allows.

As a consequence, we conclude that the representational mind can be conceived of as a richer (or more 'fluid;' Alexander and Grimes 2017) biosemiotic landscape than hitherto thought by approaches within the representational/computational tradition, in that different kinds of natural symbolic codes and natural symbol-manipulation techniques may be at work at every single stage of cognitive processes. To begin with, it is not at all clear that the brute-causal impact of environmental stimuli on the organism must exclusively translate into a sort of bio-iconic field, refractory to even primary forms of bio-conceptualization. As a matter of fact, the contrary is very likely the case. For example, according to recent geometric approaches to representations (Kriegeskorte and Kievit 2013), percepts appear to accommodate from the very outset to a symbolic code provided by populations of neurons that compound a multidimensional space. The activity pattern incited by a perceived stimulus corresponds to a point in such representational space (Fig. 5a). The interesting point is that patterns appear to capture dissimilarities very efficiently and, crucially, also the distance or degree of dissimilarities as a function of the distance/dissimilarity between the patterns themselves. In this, there clearly exists an element of iconicity. However, such a biosemiotic system of information packaging also offers a first substrate for conceptualization, in that it captures certain dissimilarities, whilst being insensitive to others. Consequently, it right away offers the means for "categorial divisions [...] along property dimensions of behavioral significance" (Kriegeskorte and Kievit 2013: 402). In other words, iconicity and categorization appear to go hand in hand at every point of the biosemiotic

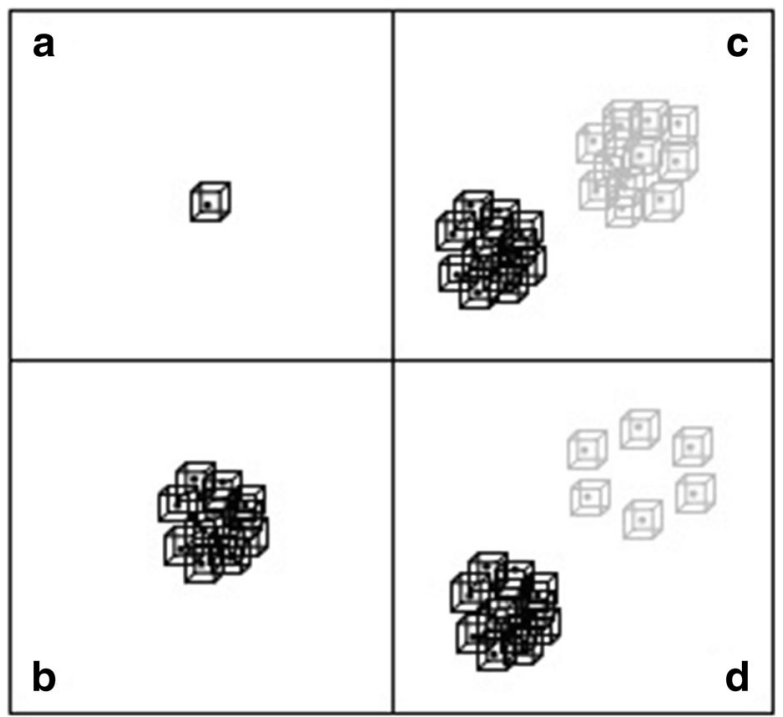

Fig. 5 Neural geometries mimic the dissimilarity distance of perceived patterns. a: The box stands for a neural geometry/representational space and the point represents a specific pattern of activity within that space. b: The set of superimposed boxes stands for geometries insensitive to differences in the perceived stimuli. c: The two separate sets of superimposed boxes stand for geometries which are selectively sensitive to some particular difference among the perceived stimuli. d: The set of superimposed boxes stands for geometries insensitive to differences among the perceived stimuli that the system is sensitive to capture as dissimilar from other perceived stimuli along different axes of differentiation 
continuum which ranges from perception to conceptualization (Bueno 2013). The trick seems to be that particular geometries, which stand for resemblance/likeness concentrations (Fig. 5b), belong to higher-level, symmetry-breaking geometric compounds at the same time (Fig. 5c,d).

Considering the issue from the opposite perspective, Fodor, year in, year out, defended that LOT cannot be but a kind of language-like, discursively organized, symbolic code of sorts, based on different kinds of arguments - see Fodor and Pylyshyn (2015: 20-32) for a synthesis. But central to all the arguments is that of compositionality. In a nutshell, conceptual thought decomposes into proper, reusable parts (i.e. properly), whereas iconic imagery merely decomposes into parts (i.e. non-properly). Conceptual thought is not iconic and is therefore conceptual discursive. So far, so good. However, if the disjunction is not exclusive, then the conclusion is a non sequitur. If the case opened in this paper is on track, serious consideration should be given to the possibility that whole areas of cognition work on an iconic-discursive basis, compatible with the reusability requirement above. Such an alternative does not necessarily rebut the LOT thesis, but it may introduce a non-trivial relaxation of Fodor's strongest implementation of the idea.

To mention just one particular illustrative case, such an amendment may have repercussions in debates around the nature of visual imagery - i.e. the activation of visual processes in the absence of visual stimuli, thus a sort of abstract visual reasoning different from visual perception. A classical position in this debate is the one of Zenon Pylyshyn (Pylyshyn 2003), explicitly supported by Fodor (Fodor and Pylyshyn 2015), which defends that these processes are conducted by LOT itself and that they are entirely discursive, despite the phenomenology of their experiential outputs. However, Stephen Kosslyn has famously opposed this thesis, based on several arguments on the base of which is the following reasoning: (1) visual imagery is performed by the same areas than primary visual processes (mostly, areas 17 and 18); and (2) primary visual areas are topologically organized; thus, (3) primary visual areas 'depict' objects both in visual perception and visual imagery (Kosslyn 1980; Kosslyn 2005, for an updated synthesis). The following qualification by Kosslyn himself is relevant:

By "depict" I mean that each part of the representation corresponds to a part of the object such that the distances among the parts on the object are reflected (albeit not perfectly) by the distances among the representations of the parts. (Kosslyn 2005: 336)

It is important to add that Kosslyn imageries are further enriched by different kinds of information, including information coded in a LOT-like discursive format. Consequently, Pylyshyn's and Kosslyn's approaches are not fully incompatible, but perhaps to a certain extent overlapping and complementary ones.

Considering all things altogether, we conclude that the representational mind appears to display its computational powers within representational fields which are, to a lesser or greater degree, both iconic and discursive, from the very inception of cognitive computations to the point where representations are ultimately subserved to the 
performance systems which underlie behavior. The exact extent of iconicity/ discursiveness of different representational stages is obviously a matter empirical, and worth consideration. ${ }^{15}$

\section{Concluding Remarks}

In this paper we have claimed that a representational modality based on units that behave iconically and discursively at the same time is not merely conceivable, but also arguably exists. We have adduced the case of an artificially crafted, external sign system that displays the blend under consideration, as well as the case of the sign or gestural variants of natural language. The latter are particularly relevant, since they exhibit (mutatis mutandis) full parallels with spoken variants in terms of developmental path, implication of brain specializations, pathological affectations, etc. Consequently, if our analysis is on track, sign languages might be seen as the epitome of the iconicdiscursive representational regime, in the same way as spoken languages are pinpointed as the epitome of the discursive regime; they might even be seen as the window through which the study of a putative mental internal language with the relevant properties can turn tractable — not unlike Fodor's classical strategy regarding LOT.

The main lesson to be learnt from this paper is that the frontier between the cardinal iconic and discursive representational modalities could turn out not to be as rigid as commonly thought, and that the representational/computational mind may have more resources within its grasp than simply the restrictive toolkit that Fodor believed to be operative in that realm. Empirical psychology has correspondingly a broader (and more attractive) task when devoted to disentangling the resources that the representational mind resorts to.

Acknowledgements This paper has benefitted from a grant of the Spanish Government (Ministerio de Ciencia, Información y Universidades, Ref. FFI2017-87699P). The authors want to express their gratitude to the reviewers for their helpful and insighfiul comments. All remaining errors are our own.

\section{References}

Alexander, V. N., \& Grimes, V. (2017). Fluid biosemiotic mechanisms underlie subconscious habits. Biosemiotics, 10, 337-353.

Atkin, A. (2013). Peirce's theory of signs. In E.N. Zalta (Ed.), The Stanford encyclopedia of philosophy (Summer 2013 Edition), URL = http://plato.stanford.edu/archives/sum2013/entries/peirce-semiotics/.

Balog, K. (2009). Jerry Fodor and non-conceptual content. Synthese, 170(2), 311-320.

Barbieri, M. (2009). Three types of semiosis. Biosemiotics, 2, 19-30.

Barbieri, M. (2013). Organic semiosis and Peircean semiosis. Biosemiotics, 6, 273-289.

Beni, M. D. (2017). The code model of biosemiotics and the fate of the structuralist theory of mental representation. Biosemiotics, 10, 99-107.

Bermúdez, J., \& Cahen, A. (2015). Nonconceptual mental content. In E.N. Zalta (Ed.), The Stanford encyclopedia of philosophy (Fall 2015 Edition), URL = http://plato.stanford.edu/archives/fall2015 /entries/content-nonconceptual/.

\footnotetext{
${ }^{15}$ From a comparative/evolutionary perspective, we believe that this conclusion may benefit projects based on exploring the continuity between the combinatorial means of the human linguistic mind and other combinatorial dimensions of the human and nonhuman mind (Cerrone 2018; Filippi 2014).
} 
Brentano, F. (1874/1973). Psychology from an empirical standpoint. London: Routledge and Kegan Paul.

Bueno, O. (2013). Perception and conception: Shaping human minds. Biosemiotics, 6, 323-336.

Campbell, R., MacSweeney, M., \& Waters, D. (2007). Sign language and the brain: A review. Journal of Deaf Studies and Deaf Education, 13(1), 3-20.

Camps, E. (2007). Thinking with maps. Philosophical Perspectives, 21, 145-182.

Casati, R., \& Varzi, A. C. (1999). Parts and places. Cambridge: The MIT Press.

Cecilia Tejedor, A. (2004). Mil palabras con las manos... del léxico signado español. Madrid: CEPE

Cerrone, M. (2018). Umwelt and ape language experiments: On the role of iconicity in the human-ape pidgin language. Biosemiotics, 11, 41-63.

Chemero, A. (2009). Radical embodies cognitive science. Cambridge: The MIT Press.

Farias, P., \& Queiroz, J. (2006). Images, diagrams, and metaphors: Hypoicons in the context of Peirce's sixtysix fold classification of signs. Semiotica, 162, 287-307.

Filippi, P. (2014). Specifically human: Going beyond perceptual syntax. Biosemiotics, 7, 111-123.

Fodor, J. A. (1998). Concepts. Were cognitive science went wrong. Oxford: Oxford University Press.

Fodor, J. A. (2003). Hume variations. Oxford: Oxford University Press.

Fodor, J. A. (2007). The revenge of the given. In B. P. McLaughlin \& J. Cohn (Eds.), Contemporary debates in philosophy of mind (pp. 105-116). Oxford: Blackwell.

Fodor, J. A. (2008). Lot 2. The language of thought revisited. Oxford: Oxford University Press.

Fodor, J. A., \& Pylyshyn, Z. (2015). Minds without meanings. An essay on the content of concepts. Cambridge: The MIT Press.

Goldberg, A. (1995). Constructions. A construction grammar approach to argument structure. Chicago: University of Chicago Press.

Goldin-Meadow, S. (2003). The resilience of language: What gesture creation in deaf children can tell us about how all children learn language. New York: Psychology Press.

Haugeland, J. (1998). Having thought. Essays in the metaphysics of mind. Cambridge: Harvard University Press.

Hickok, G., Bellugi, U., \& Klima, E. S. (1998). The neural organization of language: Evidence from sign language aphasia. Trends in Cognitive Science, 2(4), 129-136.

Hume, D. (1738/2007). In D. F. Norton \& M. J. Norton (Eds.), A treatise of human nature (Vol. 1). Oxford: Clarendon Press.

Johnson, K. (2015). Maps, languages, and manguages. Rival cognitive architectures? Philosophical Psychology, 28(6), 815-836.

Johnson, M. (1987). The body in the mind. In The bodily basis of meaning, imagination, and reason. Chicago: University of Chicago Press.

Kosslyn, S. M. (1980). Image and mind. Cambridge: Harvard University Press.

Kosslyn, S. M. (2005). Mental images and the brain. Cognitive Neuropsychology, 22(3/4), 333-347.

Kriegeskorte, N., \& Kievit, R. A. (2013). Representational geometry: Integrating cognition, computation, and the brain. Trends in Cognitive Science, 17(8), 401-412.

Kulvicki, J. (2003). Image structure. The Journal of Aesthetics and Art Criticism, 61(4), 323-340.

Kulvicki, J. (2015). Maps, pictures, and predication. Ergo 2. https://doi.org/10.3998/ergo.12405314.0002.007.

Owen, D. (2009). Hume and the mechanics of mind. Impressions, ideas, and association. In D. F. Norton \& J. Taylor (Eds.), The Cambridge companion to Hume (pp. 70-104). Cambridge: Cambridge University Press.

Peirce, C. S. (1931). Collected papers. I. Principles of philosophy. II. Elements of logic. Cambridge: The Belknap Press of Harvard University Press.

Pitt, D. (2018). Mental representation. In E.N. Zalta (Ed.), The Stanford encyclopedia of philosophy (winter 2018 edition), URL $=$ http://plato.stanford.edu/archives/win2018/entries/mental-representation/.

Poizner, H., Klima, E., \& Bellugi, U. (1987). What the hands reveal about the brain. Cambridge: The MIT Press.

Pylyshyn, Z. (2003). Seeing and visualizing. It's not what you think. Cambridge: The MIT Press.

Rescorla, M. (2009). Predication and cartographic representation. Synthese, 169(1), 175-200.

Sampson, G., \& Chen, Z. (2013). The reality of compound ideographs. Journal of Chinese Linguistics, 41(2), 255-272.

Sellars, W. (1979). Naturalism and ontology. Atascadero: Ridgeview Publishing.

Senghas, A., Kita, S., \& Ozyürek, A. (2007). Children creating core properties of language: Evidence from an emerging sign language in Nicaragua. Science, 305(5691), 1779-1782.

Sterelny, K. (1990). The representational theory of mind. An introduction. Oxford: Wiley-Blackwell.

Stjernfelt, F. (2015). Dicisings. Peirce's semiotic doctrine of propositions. Synthese, 192(4), 1019-1054.

Publisher's Note Springer Nature remains neutral with regard to jurisdictional claims in published maps and institutional affiliations. 